\title{
Cardiovascular Risk Factors in Adolescence
}

\author{
Elisabete Ramos \\ Serviço de Higiene e Epidemiologia, Faculdade de Medicina da Universidade do Porto
}

The present review will examine the relationships among behavioural and biological cardiovascular risk factors during adolescence and cardiovascular disease later in adult life.

A consistent finding is the co-occurrence of behavioural cardiovascular risk factors such as smoking, alcohol consumption, unhealthy diets and physical inactivity. Although there are no consensual criteria to define adolescence overweight, it is the most prevalent cardiovascular risk factor representing an increasingly important health problem, and the increase in the prevalence overweight, among younger age groups, is likely to have effect on others biological cardiovascular risk factors during adolescence and long-term implications for cardiovascular disease. A cluster of risk factors that includes overweight, hypertension, dyslipidemia and insulin resistance was described in children and adolescents, leading to the hypothesis that the clustering process begins early in life and persists in adulthood

Key-words: cardiovascular disease; adolescent; risk factors; child.

ARQUIVOS DE MEDICINA, 21(1):25-35

\section{INTRODUCTION}

One in every five people worldwide is someone between 10 and 19 years of age, an adolescent, as defined by the World Health Organization (1). According to the 2001 cense of the Portuguese population, this age group represents $15 \%$ of the total population (2).

Adolescence represents the transition from childhood to adulthood, a time of rapid physical, emotional and psychological changes, accompanied by biological developments characterized by evolving growth and maturation. During adolescence there is a rapid acquisition of new capacities and many situations are faced by the first time. Early adolescence consists on the rapid biological changes and the adjustment to them. Separation from the parents begins. Normally, turmoil is greatest during this phase. In adolescence proper sexual development continues, the cognitive skills of a young person become enhanced and the capacity to integrate one's experiences and emotions improves. Late adolescence is characterized by increased interest in future goals and many choices concerning adult life are made. Separation from parents proceeds, and the teenager begins to consider what he or she wants in life and what their own ideals will be $(3,4)$.

Adolescents are generally thought to be healthy. By the second decade of life they have survived the diseases of early childhood, have a low incidence of infections such as pneumonia and gastroenteritis compared with younger children and the overwhelming health problems associated with ageing are still many years away. It is probably one of the reasons why they have generally been given little health attention considering chronic diseases. The World Health Organization estimated that one million individuals aged 10 to 19 years old lose their life annually, mostly as a consequence of accidents, suicide and other forms of violence (5). In Portugal, in 2001, the death rate in the 15 to 24 years old group was 74.1 per 100,000 males and 14.2 per 100,000 females, the mortality rate due to traffic accidents being 45.3 and 9.7 per 100,000, respectively (6).

Although a generally healthy period, adolescence is the opportunity to prepare for a healthy adult life, and to prevent the onset of behaviours that will affect health and well being later in life (1). The World Health Report 2002 (7) indicated that by 2020 it is expected that the major noncommunicable diseases accounted for almost $73 \%$ of all deaths and $60 \%$ of the global burden of disease. Preventable biological risk factors as high blood pressure, high blood cholesterol and overweight, and related major behavioural risk, as unhealthy diet and physical inactivity, underlie four of the most prominent noncomunicable diseases - cardiovascular diseases, cancer, chronic obstructive pulmonary disease and type 2 diabetes.

Adolescence gives not only opportunities for progress but also a period when important threats are presented. Many behavioural patterns are developed during adolescence will last for life and habits learned in childhood and adolescence will be carried over into adulthood when they will be more difficult to change $(1,3)$.

\section{BEHAVIOURAL RISK FACTORS}

Chronic diseases result from a complex interaction between genetic and environmental factors. The environmental factors, by its modifiable nature, represent the 
major target to preventive measures. Since many lifestyle changes are difficult to achieve in adulthood and even harder to maintain over a long-term period, it seems reasonable to attempt to change these risk factors early in life.

Behaviours such as smoking, alcohol consumption, unhealthy diets and physical inactivity are the leading causes of the major non-communicable diseases, including cardiovascular diseases, in adults (7-9). For most of these risks a substantial proportion of attributable disease burden occurred among those with modest elevations of risks (9).

Atherosclerosis constitutes an important contributor to cardiovascular diseases. This process is initiated early in life, however the clinical outcome of the atherosclerosis being usually detected only in adult life $(10,11)$. Thus, the full effect of exposure to behavioural risk factors during childhood and adolescence will only be seen in the future. This means that the time lag effect of the exposure to risk factors on cardiovascular diseases is large, which may explain what adolescents have generally been given little importance. On the other hand, many of the behavioural patterns acquired during adolescence (such as the use of tobacco, alcohol and other drugs, eating habits, and physical activity or inactivity) may last a lifetime (1).

Health and education are strongly linked. To maintain good health and avoid preventable disease throughout their lives, children and adolescents must acquire knowledge about health risks and acquire the skills that are needed to avoid or reduce those risks. It is a learning process that begins in childhood and is constantly updated in adulthood. Adolescents are receptive to new ideas; they are keen to make the most of their growing capacity for making decisions. Their curiosity and interest are a tremendous opening to foster personal responsibility for health. Furthermore, engaging in positive and constructive activities provide occasions to acquire behaviours that are crucial to adult health (1). Despite knowledge is associated with lower risk behaviours it is not a sufficient guarantee for prudent choices $(12,13)$.

\section{Smoking and Drinking}

Cigarette smoking results in enormous morbidity and mortality burden. The World Health Report showed that the estimated number of attributable deaths in the year 2000 was 4.9 million (7). Among industrialized countries, smoking is estimated to cause over $90 \%$ of lung cancer among men and about $70 \%$ of lung cancer among women. Also, it is estimated that $56-80 \%$ of chronic respiratory diseases and $22 \%$ of cardiovascular diseases are attributable to smoking (7). In the World Health Organization European sub-region with very low child and adult mortality, of which Portugal is part, smoking is the major contribute to the lost healthy life (DALYs) in males (8).

According to the World Health Organization, about 150 million adolescents use tobacco and it is estimated that 75 million of them will die of tobacco-related diseases later in life (14). Because most smokers acquire their habit in their teens (15), to quantify smoking, to describe age of initiation and its determinants is essential to prevention. Smoking at young ages also represents a real risk of death in later life [16], but also in the short term as previously reported when the association between early atherosclerotic lesions with cigarette smoking in youths was found $(17,18)$.

In Portugal, data from the National Health Surveys conducted in 1995-6 (17.989 men; 20.249 women) and 1998-9 (17.923 men; 20.302 women), showed a noticeable higher prevalence of smoking in males but decreasing from $33.3 \%$ in 1987 to $29.3 \%$ in 1999 . However, in women, it increased from $5.0 \%$ to $7.9 \%$ during the same period (19). Also, regional differences in smoking prevalence were observed across the country (19). Data obtained as part of an ongoing cross-sectional health and nutrition survey of urban adults living in Porto during 1999-2000 showed that the overall prevalence of smokers was $24.3 \%$ (95\% confidence interval 22.2-26.4). Men had a significantly higher prevalence of smoking (35.0\%; $95 \%$ confidence interval $31.3-38.8$ vs. $17.6 \%$; $95 \%$ confidence interval 15.4-20.1) and, on average, smoked a larger number of cigarettes per day $(21.2$; $95 \%$ Confidence Interval $(\mathrm{Cl}): 12.4-15.0$ vs. $14.1 ; 95 \% \mathrm{Cl}$ : $19.6-$ 22.6) (20).

Smoking behaviour in Portuguese adolescents was studied on different samples. A cross-sectional study was carried out on smoking habits comprising 1052 girls and 984 boys aged 13 years attending public and private schools in the city of Porto and $19.9 \%$ students only had ever experimented smoking but were not smokers; $1.8 \%$ were occasional smokers and $1.3 \%$ smoked at least one cigarette/day (21). Using a sample of students of 25 schools from five municipalities near Lisbon $(n=3064)$, $71.3 \%$ were never smokers, $21.9 \%$ smoked less than monthly, $2.1 \%$ monthly and $4.7 \%$ weekly or more frequently (22).

Smoking is also associated with characteristics that may contribute to a higher cardiovascular risk. A national survey that analysed the mean income and expenses of Portuguese families in the year 2000 found an inverse relation between education and the proportion of income of each family that is spent with tobacco (23). Also the results from a sample of urban adults living in Porto [20], found education and gender as the major determinants of smoking. Adolescents smokers had lower school achievement, had more money available to spend and were more likely to perform various risky behaviours $(21,22,24)$. It is also associated with less physical exercise (24-26).

Worldwide alcohol consumption is responsible for $3.2 \%$ of deaths (1.8 million). Within sub-regions the proportion of disease burden attributable to alcohol is greatest in America and Europe where it ranges from $8 \%$ to $18 \%$ of total for males and $2 \%$ to $4 \%$ for females (7). Alcohol consumption was estimated to cause, worldwide, $20-30 \%$ of oesophageal cancer, liver disease, epilepsy, motor vehicle accidents, and homicide or other intentional injuries (7). Alcohol intake during adolescence has also consequences in both short and long term in life (27). 
A common pattern of alcohol consumption among adolescents is heavily episodic drinking, defined as consuming five or more drinks on a single occasion. The earlier an adolescent starts drinking increased risk of being longterm consumers and greater is the chance of developing a clinical alcohol disorder as an adult $(27,28)$.

Prevalence of reported alcohol consumption decreased slightly between the National Health Surveys, from $65.7 \%$ in $1995 / 1996$ to $64.0 \%$ in $1998 / 1999$ in male, and from $26.9 \%$ to $26.0 \%$ in females (29). However the decreased in prevalence of alcohol consumption, the amount of beer, whiskey, and Port wine consumed increased among male drinkers, and younger generations, males and females, are shifting from wine to beer and spirits (29).

A consistent finding is the co-occurrence of tobacco and alcohol use. Drinkers are more likely to smoke than non-drinkers, and smokers are more likely to drink than non-smokers $(21,22,30)$. However most of the studies on the alcohol and tobacco relationship have been of a cross-sectional or retrospective nature and results that have been found in longitudinal studies have been inconclusive. Some prospective studies have suggested that alcohol use predicts cigarette use more strongly than the converse $(31,32)$, while other longitudinal studies identified that cigarette use was particularly important for subsequent involvement in alcohol use (33-35). Results from a large international sample of European adolescents $(n=10170$, mean age $=13.3$ years), including Portuguese adolescents, revealed that in Europe as a whole, tobacco use predicted subsequent alcohol use better than the converse (30).

\section{Diet}

Accumulated scientific research on the relation between diet and chronic diseases and the possible childhood origin of those diseases (36-38) has focused attention on the need to know children's diet. During adolescence, nutritional problems originated earlier in life can potentially be corrected in addition to addressing current ones. It is also a timely period to shape and consolidate healthy eating and lifestyle behaviours, thereby preventing or postponing the onset of nutrition-related chronic diseases in adulthood (1).

The rapid rise in obesity in recent decades indicates the relative importance of environmental influences for this epidemic. Part of the problem with childhood overweight and obesity is that children are not exhibiting healthy dietary habits. Diets high in saturated fat, cholesterol, sugar, and salt and low in whole grains, low-fat dairy, fruits and vegetables, have a strong association with being overweight (39-41).

Food consumption data suggest that infants are currently exposed to a wide variety of foods that tend to be high in fat and sugar, including excess French fries, nutrient-poor snacks and juice-based sweetened beverages (42).

The available science strongly supports the recommendations to reduce population soft drink consumption.
A recently meta-analysis of 88 studies found clear associations of soft drink intake with increased energy intake and body weight, and also was associated with lower intakes of milk, calcium, and other nutrients and with an increased risk of diseases (43).

High of fruits and vegetables intake are associated with reduced risk for chronic disease, but adolescents intake are often inadequate $(42,4445)$ and longitudinal trends indicated that adolescents decreased their daily fruit and vegetables intake during the transition from early to middle adolescence and from middle to late adolescence (46).

The link between childhood dietary behaviours and the risk of diseases in adulthood suggests that the development of healthy behaviours particularly those related to diet will decrease the incidence of chronic diseases over the course of life. Results from a childhood to adult cohort study indicated that an increase in fruits and vegetables intake was associated with decreased risk of cancer over a 60 -year period (47).

Only a limited number of longitudinal studies have investigated the extent of tracking of nutrient intakes from adolescence into young adulthood and the results have been inconsistent. In the Amsterdam Growth and Health Longitudinal Study, significant stability coefficients between 13 and 33 years of age were found for all nutrients, but over the study period dietary intake between adolescence and adulthood was changeable (48). Data from a Norwegian longitudinal cohort found some stability of eating behaviour between 14 and 21 years old, despite the overall changes in mean weekly frequency of consumption (49). A poor to moderate correlation for most nutrient intakes was reported on subjects aged 18-30 years over a 7-year period but, and dietary nutrient-intake patterns may be changing differentially over time among individuals. These results indicated that, despite considerable changes in lifestyle, individuals tend to remain within broad categories of intake (50). A study that evaluated the tracking of energy and nutrient intakes between 15 and 20 years of age found only a poor to fair tracking of energy and nutrients in both sexes indicating substantial drift of individuals between classes of intake over time (51).

Despite the inconsistent results based on the evidence that dietary patterns developed during childhood persist into adulthood (52) and on results indicating that adolescents usually ate what they liked to eat, and the decision about what to eat was made because of the taste of the food without regard for any health consequence or negative health outcomes (53), dietary interventions aimed the prevention of chronic diseases, such as obesity and cardiovascular diseases, should be targeted at children and help them to form healthy dietary habits (42).

Knowledge is associated with lower risk behaviours but it is not a sufficient guarantee for prudent choices $(12,13)$. Adolescents understand that there may be negative consequences resulting from the daily choices that they make. It is clear that culture and family customs have a great influence on the direction students take in their 
dietary practices, as well as their involvement in physical activity. The convenience and easy accessibility of low nutritious foods is also seen as a contributing factor, as well the negative influences that are presented through advertising of non-nutritious foods (53).

\section{Physical Activity}

There is no internationally agreed definition or measure of physical activity or inactivity. Therefore, a number of direct and indirect data sources and a range of survey instruments and methodologies were used to estimate activity levels (7) which may difficult the results comparability.

Results suggest that modern inactive lifestyles are at least - if not more - as important as diet in the aetiology of obesity. The global estimate for prevalence of physical inactivity among adults is $17 \%$, ranging from $11 \%$ to $24 \%$ across the 14 Word Health Organization sub-regions. Estimates for prevalence of some but insufficient activity ( $<2.5$ hours per week of moderate activity) ranged from $31 \%$ to $51 \%$, with a global average of $41 \%$ across the same Word Health Organization sub-regions. Overall, physical inactivity was estimated to cause 1.9 million deaths $(7,9)$. Data from a population based case-control study to myocardial infarction allow estimate to a Portuguese population that a population attributable fraction of $37.8 \%$ for females and $37.7 \%$ for males to physical inactivity (54).

Physically active during adolescence is a health determinant in adulthood $(55,56)$, also present a role of healthy effects in adolescence. The health benefits associated with an active lifestyle in children and adolescents include weight control, and lower blood pressure. Also, evidence was provided that adolescents engaging in physical activities are positively associated with self-esteem $(57,58)$ and associated with reduced participation in a series of health risk behaviours as cigarette and marijuana intake $(59,60)$, sexual intercourse $(61,62)$. In contrast, Aaron et al show a higher risk for initiating alcohol consumption between the most active males or males who participated in competitive athletics than their less active counterparts (63).

Additionally, physically active lifestyle during infancy and adolescence, it predisposes to increased physical activity in adulthood and the maintenance of a physically active lifestyle to help prevent the development of cardiovascular risk factors $(15,64)$. Children establish a sedentary lifestyle at a young age (65) and participation in organized athletics diminishes greatly after middle school. This is true for both genders, however it had a major effect on girls (64). In addition to this, socioeconomic factors place certain subpopulations at greater risk to be more prone to the problem $(15,64)$.

Changes in living patterns have led to less physical activity and less physical labour. Physical activity in children and adolescents has diminished for a variety of reasons. Changing family makeup, with increasing numbers of households with two working parents or a single parent, limits the ability of parents to encourage participation and to provide access to regular after-school physical activities (15). Children tend to walk or cycle less and increasingly rely on cars for transportation. A trend away from active leisure pursuits and recreational sports has been evident as well as a reliance on sedentary entertainment, including television and computers, has increased (15). The increasing time spent with the television and the computer are reasons why people spend many more hours of the day seated and relatively inactive than a generation ago (7). The American Academy of Pediatrics recommends that television watching for children should be limited to 1-2 hours per day (66). In a national, schoolbased sample of Portuguese adolescents aged 11-16 years, $71.7 \%$ of the adolescents were watching television up to $3 \mathrm{~h}$ a day, and $28.3 \%$ were watching $4 \mathrm{~h}$ or more (67).

Interventions to increase physical activity in high school students should target adolescents of all shapes and sizes, and may best be achieved by school policies requiring physical education or after-school sports. Activities that result in significant energy expenditures in children may include recreational and organized or competitive sporting activities. Knowledge about the prevalence of risk factors and understanding their determinants are essential to planning useful prevention actions.

\section{BIOLOGICAL RISK FACTORS}

According the World Health Report 2002 of the World Health Organization, more than three-quarters of cardiovascular diseases result from tobacco consumption, high blood pressure, cholesterol or a combination of them (7).

Observations from autopsy studies, such as the Bogalusa Heart Study and the Multicentre Pathobiological Determinants of Atherosclerosis in Youth Study, documented a strong correlation between coronary atherosclerosis and cardiovascular risk factors in young people $(10,18)$. Also, childhood measures of body mass index and low density lipoprotein cholesterol (LDL-cholesterol) level predict carotid artery intima-media thickness, a measure of atherosclerosis, in adults (68).

The presence of multiple risk factors increases markedly the extent of atherosclerotic lesions in the coronary vessels, supporting the concept of a synergistic effect between behavioural and biological factors $(69,70)$. The association between early atherosclerotic lesions and high cholesterol levels, glycohemoglobin, obesity and hypertension have been reported in youths $(17,18,69,71)$. Additionally, previous studies showed that the extent of atherosclerostic change in children and young adults correlated with the identification of the same risk factors in adults, as cigarette smoking, physical activity/inactivity, obesity, hypertension, and insulin resistance $(15,68)$.

The relation of the risk factors to the increasing extent of raised lesions in arteries in young adults, and results that found a tracking of these risk factors across life, indicates that precursors of atherosclerosis and essential hypertension begin early in life. Those observations sug- 
gest that risk factor modification should be initiated early in life.

\section{Overweight and Obesity}

Overweight and obesity are important determinants of health. The World Health Organization (WHO) estimates that there are more than 300 million obese and 1.4 billion overweight people worldwide. Without action, these numbers are projected to rise to nearly 500 million obese people and nearly 2 billion overweight by 2010 (7). According the World Health Report 2002 obesity is killing about 220.000 men and women a year in the United States of America and Canada alone, and about 320000 men and women in 20 countries of Western Europe (7). In Europe, obesity rates in adults have increased in most countries and overall rates above $25 \mathrm{~kg} / \mathrm{m}^{2}$ indicate a continuing population shift away from the considered normal healthy range of body mass index. Even in those countries regarded as being favoured with lower rates of obesity, there is clear evidence of increasing trends (72). Which may increase the previously estimate, for European Union, of at least one in 13 annual deaths as attributable to excess weight (73).

Data from the National Health Surveys, showed an increase of the crude prevalence of obesity and overweight in males. The prevalence of overweight increased from $39.9 \%$ to $42.5 \%$ and the prevalence of obesity increased from $10.3 \%$ to $11.5 \%$. In females, the crude prevalence of obesity increased from $12.7 \%$ in $1995-6$ to $14.2 \%$ in 1998-9, whereas the prevalence of overweight remained stable, $32.2 \%$ in $1995-6$ and $32.3 \%$ in $1998-9$ (74). The increase is also observed in young Portuguese males in the period ranging from 1994 to 1999 , as reflected in the data from the conscription military service obtained from medical records (in this period, the medical examination was compulsory at the age of 20 for all the males and only in special circumstances could be delayed or postponed), the prevalence of obesity increased from $1.4 \%$ to $2.3 \%$ and overweight from $15.0 \%$ to $22.0 \%$ (75). In a sample of adults from Porto, the overall prevalence of obesity was $21.3 \%$, and overweight was $41.8 \%$. Overweight prevalence was higher in males (49.9\%) than females $(36.5 \%)$, but obesity was more prevalent in women (26.1 vs. $13.9 \%$ ) (76)

Also, obesity is globally increasing in young people $(72,78,79)$, once thought as a disease of adulthood, is emerging in children and adolescents. The increasing risk for a large number of social and health problems accompanied adolescence overweight trends over the last several decades and it is likely to have a great impact on the future cardiovascular health $(4,55,80)$. Also, an obese adolescent is at risk of becoming an obese adult with an associated raised risk of disease and premature death $(55,80-83)$.

Childhood and adolescence are critical periods for the onset of obesity $(4,84)$. During adolescence changes in absolute and percentage body fat take place. In general total body fat mass increases in girls but, in boys, the percentage body fat decreases as a result of an increase in fat-free mass (4).

The mechanisms linking excess body fat and diseases are under intensive investigation, but still far from clear. It may seem strange to put a lot of effort into studies on the prevalence of overweight and obesity in children, since it is rather unusual that children become sick from their overweight. However, obesity in this age group is not usually a benign condition. Despite the associations are much stronger in adulthood, overweight and obese adolescents and young adults have more arterial lesions $(10,71)$, metabolic complications as non insulin-dependent diabetes mellitus and features of the metabolic syndrome (85-88), psychological problems (89), a reduced capacity for physical activity $(90,91)$ and other risk factors $(85,92)$.

Defining obesity in children has been difficult because assessing body fat is expensive and impractical in large groups. Though body mass index is only an indirect measure of fatness, the International Obesity Task Force and the WHO recommended it to classify overweight in children and adolescents $(93,94)$. However, there are no consensual criteria to define the boundaries of what is called adolescence overweight made difficult the comparability of results.

In American children and adolescents, overweight more than doubled between 1976-1980 and 1999-2000 (87). In England, the fastest increase was observed during the nineties and overweight prevalence almost tripled (72). In Southern European children aged 7 to 11 years the prevalence of overweight ranges from $20 \%$ to $35 \%$, while in Eastern Europe it is lower than $20 \%$, probably reflecting the social and economic conditions that followed the political transition in the late nineties (72). Portuguese 9-year-old children showed a mean body mass index increase of $2.3 \mathrm{~kg} / \mathrm{m}^{2}$ from 1970 to 2002 (77). Using a representative community sample of $13-$ year-old adolescents from public and private schools, members of the Epidemiological Health Investigation of Teenagers in Porto (EPITeen) cohort, was found a prevalence of overweight (more than $95^{\text {th }}$ percentile) was $10.2 \%$ and an additional $16.5 \%$ were at risk of overweight (between the $85^{\text {th }}$ percentile and the $95^{\text {th }}$ percentile) (95). And results stress the preventive role of physical activity and the importance of parental body mass index as a simple marker of overweight risk in adolescents.

The magnitude of the problem varies among countries and age groups $(72,78,96)$. It is the result of a heterogeneous group of conditions, which includes genetic and environmental factors, and reflects social, behavioural, and physical elements with wide geographical impact (96). Prevention of overweight is a complex issue. It warrants changes in individual and family behaviours, in food marketing and in the overall social environment $(96,97)$. Schools are an especially effective setting to provide adolescents with long-lasting healthy dietary habits (98). To curb the epidemic and to evaluate community programs, it is essential to have more extensive knowledge on the prevalence of overweight. A thorough under- 
standing of the causes and determinants of the obesity epidemic at international and local level are essential because different factors might operate and cluster in different regions calling for different interventions to be adequate $(72,96,97)$.

\section{Hypertension}

Worldwide, high blood pressure is estimated to cause 7.1 million deaths, about $13 \%$ of the total death (7). Globally, about $62 \%$ of cerebrovascular disease and $49 \%$ of ischaemic heart disease are attributable to suboptimal blood pressure (systolic $>115 \mathrm{mmHg}$ ) (7). Across World Health Organization regions, the range between the highest and lowest age specific mean systolic blood pressure levels is estimated to be at about $20 \mathrm{mmHg}(7)$. In the European subregions, which include Portugal, blood pressure levels are particularly high (7). Despite heterogeneity among countries, European countries had higher blood pressure than United States and Canada (99).

Traditionally, hypertension has been considered a problem of adults but earlier stages of life are critical in its etiology. Early-life blood pressure is associated with increased cardiovascular risk (100) and blood pressure levels tracks from childhood into adulthood. Long-term follow-up studies have shown that blood pressure levels measured in childhood and adolescence are positively associated with blood pressure in early adulthood and showna clear association between elevated blood pressure level in late adolescence or young adulthood, and cardiovascular morbidity and mortality (101-103).

In a Portuguese adult population aged 18-90 years old an overall $42.1 \%$ had hypertension. The age-specific prevalence of hypertension in persons younger than 35 years, 35-64 years old and older than 64 years old, was $26.2 \%, 54.7 \%$ and $79 \%$ in men and $12.4 \%, 41.1 \%$ and $78.7 \%$ in women, respectively (104). Using a representative sample of adults living in Porto, found $68.0 \%$ females and $73.5 \%$ males with a blood pressure $(130 / 85 \mathrm{mmHg}$ (105). Additionally, a lower proportion of awareness and control was found in the adult Portuguese population. Among hypertensive patients, only $46.1 \%$ were aware of their high blood pressure, $39.0 \%$ were taking antihypertensive medication, but only $11.2 \%$ achieved blood pressure control (<140/90 mmHg) (104).

Since blood pressure levels in adulthood are directly related to those in childhood and adolescence (102), it is reasonable to suppose that the values in Portuguese adolescents are higher than those of other populations when the prevalence of hypertension is lower.

Data from the EPITeen study that evaluated 2023 adolescents aged 13-years-old and enrolled at public and private schools of Porto, found a prevalence of hypertension (if systolic (SBP) and/or diastolic blood pressure (DBP) were above the 95th percentile for gender, age and height) of $22.0 \%$ and $13.3 \%$ of hypertension (SBP or DBP levels were above the 90 th percentile but both $<$ the $95^{\text {th }}$ percentile) (106). Mean systolic and diastolic blood pres- sure measured in this study were similar to those described previously for this age-group in a sample of 86 adolescents in the Porto area (107) and in an unspecified number of girls in the north of the country (108), but higher than those in boys from the Northern of Portugal (108). The results also found that body mass index was related to blood pressure (106).

While control of hypertension in adults is beneficial to reduce the occurrence of cardiovascular disease and mortality $(109,110)$, the identification of means of preventing hypertension in earlier life is important, especially in a population such as the Portuguese that shows a high prevalence of this health problem and has stroke a major cause of death.

\section{Metabolic Syndrome}

Most individuals who developed cardiovascular diseases presented multiple risk factors. This cluster of risk factors, that usually includes overweight, hypertension, dyslipidaemia and insulin resistance, was initially called "syndrome X" (111). Syndrome features are associated with insulin resistance and through this common pathway result in a high-risk state for developing type 2 diabetes and cardiovascular events among adults (112). Recently, the "Third Report of the National Cholesterol Education Program Expert Panel on Detection, Evaluation, and Treatment of High Blood Cholesterol in Adults" (ATPIII) recognized as characteristic factors of the metabolic syndrome abdominal obesity, atherogenic dyslipidemia (elevated triglyceride, small LDL particles, low HDL cholesterol), raised blood pressure, insulin resistance (with or without glucose intolerance), and prothrombotic and proinflammatory states. It also provided simplified clinical diagnostic guidelines for the adult metabolic syndrome (113).

A similar clustering of risk factors was described in children and adolescents but in this age group there is no agreement on the syndrome definition (114-117). In the absence of a commonly agreed definition, different component features and several cut points have been used to consider the presence of metabolic syndrome in adolescents. Several studies investigated the determinants and the effects of the individual component factors of metabolic syndrome in children and adolescents, and their main finding was that they tend to track through adulthood $(55,81,118,119)$. This leads to hypothesise a similar behaviour for metabolic syndrome when considered a single entity, and to admit that the clustering process begins early in life, and persists into adult life.

To identify disparities in the World Health Organization and ATPIII definitions of metabolic syndrome when extended to adolescents, Goodman et al (120) defined metabolic syndrome using the adult cut-off points, except for body mass index. The resulting ATPIII-defined prevalence was $4.2 \%$ and the $\mathrm{WHO}$-defined prevalence was $8.4 \%$. In Mexico, using five different approaches, in 10-18 years-old adolescents, the computed prevalence ranged from $3.8 \%$ to $7.8 \%$. Using ATPIII definition it was $6.5 \%$ 
(121). In The Bogalusa Heart Study a prevalence of 3.8\% was found in adolescents aged 11 to 13 years old, but considered metabolic syndrome only when four features were present (122). The overall prevalence of metabolic syndrome among adolescents examined during the $\mathrm{Na}$ tional Health and Nutrition Examination Survey (NHANES 1999-2000) was $6.4 \%$ considering the ATPIII definition modified for age but with some different cut-points, as the $90^{\text {th }}$ waist percentile to define abdominal obesity (123). Using data collected by the NHANES between 1988 and 1994 and the adapted ATPIII definition, the estimated prevalence reported among 12-19 years old adolescents was $9.2 \%(124)$.

Until recently, no data was available to describe the national prevalence of the metabolic syndrome in Portuguese adults or adolescents. In a cross-sectional study of 1436 adult residents in Porto, that defined metabolic syndrome as proposed by the ATP III, found a crude prevalence of metabolic syndrome of $23.9 \%$ with a high blood pressure as the more prevalence feature (105). The prevalence of metabolic syndrome, evaluated in 1348 adolescents aged 13 years old registered at public and private schools of Porto, was $10.5 \%$ (9.8\% in female and $11.4 \%$ in male). The most prevalent feature was high blood pressure in females (34.8\%) and low HDL in males $(40.2 \%)$ and the less frequent was fasting serum glucose $>6.1 \mathrm{mmol} / \mathrm{L}(0.6 \%)(125)$.

Previous epidemiologic identification of long-term health consequences of gestational events and outcomes widened the window of investigation to include the early origins of later disparities in well-being and health $(36,37)$. Also, we know that adverse outcomes in adulthood, such as those concerning ill health, can frequently be traced back to disadvantaged conditions earlier on, recognised that risk factors are cumulative over the life course (126).

Base on the notion that early life exposures during critical periods of growth influence children and adolescents health and shapes morbidity later in adult life (127131 ), and also on the notion that the increase of cardiovascular risk factors prevalence in adolescents, it is important to give more attention to this young age group to understand the relation between adolescent health and the incidence of diseases in adulthood, and to plan preventive measures.

\section{REFERENCES}

1 - World Health Organization, the United Nations Population Fund and the United Nations Children's Fund Jointly Convened a Study Group on Programming for Adolescent Health. Action for Adolescent Health. Towards a Common Agenda. Recommendations from a Joint Study Group. [Cited 2005 Oct]. Available From: url http://www.who.int/ child-adolescent-health/new_publications/adh/ who_frh_adh_97.9_en.pdf.
2 - Instituto Nacional de Estatística. Recenseamento da População e da Habitação (Portugal) - Censos 2001. Lisboa: Instituto Nacional de Estatística; 2003.

3 - Steinberg L. Cognitive and Affective Development in Adolescence. Trends Cogn Sci 2005;9:69-74.

4 - Cameron N, Demerath EW. Critical Periods in Human Growth and Their Relationship to Diseases of Aging. Am J Phys Anthropol 2002; suppl 35:159-84.

5 - World Health Organization. World Report on Violence and Health. 2002. [Cited 2006 Jan]. Available From: url http:// www.who.int/violence_injury_prevention/violence/ world_report/en/full_en.pdf.

6 - Direcção de Serviços de Informação e Análise. Divisão de Epidemiologia. Risco de Morrer rm Portugal, 2001. Lisboa: Direcção-Geral da Saúde; 2003. [Cited 2005 Oct]. Available From: url http://www.dgs.pt/upload/membro.id/ ficheiros/I005964.pdf.

7 - World Health Organization. The World Health Report 2002. Reducing Risks, Promoting Healthy Life. World Health Organization: Geneva; 2002. Available From: url http:// www.who.int/whr/2002/en/whr02_en.pdf.

8 - Powles JW, Zatonski W, Vander Hoorn S, Ezzati M. The Contribution of Leading Diseases and Risk Factors to Excess Losses of Healthy Life in Eastern Europe: Burden of Disease Study. BMC Public Health 2005;5:116.

9 - Rodgers A, Ezzatil M, Vander Hoorn S, Lopez AD, Lin RB, Murray CJ. Distribution of Major Health Risks: Findings from the Global Burden of Disease Study. PLoS Med 2004;1:e27.

10 - Berenson GS, Srinivasan SR, Bao W, Newman WP, Tracy RE, Wattigney WA. Association between Multiple Cardiovascular Risk Factors and Atherosclerosis in Children and Young Adults. The Bogalusa Heart Study. N Engl J Med 1998;338:1650-6.

11 - Napoli C, D'Armiento FP, Mancini FP, et al. Fatty Streak Formation Occurs in Human Fetal Aortas and Is Greatly Enhanced by Maternal Hypercholesterolemia. Intimal Accumulation of Low Density Lipoprotein and Its Oxidation Precede Monocyte Recruitment into Early Atherosclerotic Lesions. J Clin Invest 1997;100:2680-90.

12 - Frost R. Cardiovascular Risk Modification in the College Student: Knowledge, Attitudes, and Behaviors. J Gen Intern Med 1992;7:317-20.

13 - Smalley SE, Wittler RR, Oliverson RH. Adolescent Assessment of Cardiovascular Heart Disease Risk Factor Attitudes and Habits. J Adolesc Health 2004;35:374-9.

14 - World Health Organization. Overview of Child and Adolescent Health. Adolescent Health and Development. [Cited 2005 Oct]. Available From: url http://www.who.int/childadolescent-health/overview/ahd/adh_sheer.htm.

15 - Haymann LL, Williams CL, Daniels SR, et al. Cardiovascular Health Promotion in the Schools: A Statement for Health and Education Professionals and Child Health Advocates from the Committee on Atherosclerosis, Hypertension, and Obesity in Youth (Ahoy) of the Council on Cardiovascular Disease in the Young, American Heart Association. Circulation 2004;110:2266-75.

16 - McCarron P, Smith GD, Okasha M, Mcewen J. Smoking in Adolescence and Young Adulthood and Mortality in Later Life: Prospective Observational Study. J Epidemiol Community Health 2001;55:334-5.

17 - Howard G, Wagenknecht LE, Burke GL, et al. Cigarette Smoking and Progression of Atherosclerosis: The Atherosclerosis Risk in Communities (Aric) Study. JAMA 1998; 279:119-24. 
18 - Relationship of Atherosclerosis in Young Men to Serum Lipoprotein Cholesterol Concentrations and Smoking. A Preliminary Report from the Pathobiological Determinants of Atherosclerosis in Youth (Pday) Research Group. JAMA 1990;264:3018-24.

19 - Fraga S, Sousa S, Santos AC, et al. Tabagismo em Portugal. Arq Med 2005;19:207-29.

20 - Santos AC, Barros H. Smoking Patterns in a Community Sample of Portuguese Adults, 1999-2000. Prev Med 2004; 38:114-9.

21 - Fraga S, Ramos E, Barros H. [Smoking and Its Associated Factors in Portuguese Adolescent Students]. Revista de Saúde Pública 2006;40:620-6.

22 - Vitoria PD, Kremers SP, Mudde AN, Pais-Clemente M, De Vries H. Psychosocial Factors Related with Smoking Behaviour in Portuguese Adolescents. Eur J Cancer Prev 2006;15:531-40.

23 - Instituto Nacional de Estatística. Destaque do Ine: Dia do Não Fumador. Inquérito aos Orçamentos Familiares 2000 - Despesas com Tabaco. Instituto Nacional de Estatística 2002. [Cited 2005 Sept]. Available From: url http:// www.ine.pt/.

24 - Audrain-McGovern J, Rodriguez D, Tercyak KP, Cuevas J, Rodgers K, Patterson F: Identifying and Characterizing Adolescent Smoking Trajectories. Cancer Epidemiol Biomarkers Prev 2004;13:2023-34.

25 - Donato F, Assaneli D, Chiesa R, Poeta ML, Tomasoni V, Turla C. Cigarette Smoking and Sports Participation in Adolescents: A Cross-Sectional Survey among High School Students in Italy. Subst Use Misuse 1997;32:1555-72.

26 - Holmen TL, Barrett-ConnorE, Clausen J, Holmen J, Bjermer L. Physical Exercise, Sports, and Lung Function in Smoking Versus Nonsmoking Adolescents. Eur Respir J 2002; 19:8-15.

27 - Andersen A, Due P, Holstein BE, Iversen L. Tracking Drinking Behaviour from Age 15-19 Years. Addiction 2003;98:1505-11.

28 - Masterman PW, Kelly AB. Reaching Adolescents Who Drink Harmfully: Fitting Intervention to Developmental Reality. J Subst Abuse Treat 2003;24:347-55.

29 - Marques-Vidal P, Dias CM. Trends and Determinants of Alcohol Consumption in Portugal: Results from the National Health Surveys 1995 to 1996 and 1998 to 1999. Alcohol Clin Exp Res 2005;29:89-97.

30 - Wetzels JJ, Kremers SP, Vitoria PD, De Vries H. The Alcohol-Tobacco Relationship: A Prospective Study among Adolescents in Six European Countries. Addiction 2003;98:1755-63.

31 - Ellickson PL, Hays RD, Bell RM. Stepping through the Drug Use Sequence: Longitudinal Scalogram Analysis of Initiation and Regular Use. J Abnormal Psychol 1992;101:441-51 .

32 - Jackson KM, Sher KJ, Cooper ML, Wood PK. Adolescent Alcohol and Tobacco Use: Onset, Persistence and Trajectories of Use across Two Samples. Addiction 2002;97:517$-31$.

33 - Adrados JL. The Influence of Family, School, and Peers on Adolescent Drug Misuse. Int J Addict 1995;30:1407-23.

34 - Duncan SC, Duncan TE, Hops H. Progressions of Alcohol, Cigarette, and Marijuana Use in Adolescence. J Behav Med 1998;21:375-88.
35 - Lewinsohn PM, Rohde P, Brown RA. Level of Current and Past Adolescent Cigarette Smoking as Predictors of Future Substance Use Disorders in Young Adulthood. Addiction 1999;94:913-21.

36 - McMillen IC, Robinson JS. Developmental Origins of the Metabolic Syndrome: Prediction, Plasticity, and Programming. Physiol Rev 2005;85:571-633.

37 - Barker DJ. The Developmental Origins of Chronic Adult Disease. Acta Paediatr Suppl 2004;93:26-33.

38 - Ness AR, Maynard M, FrankelL S, et al. Diet in Childhood and Adult Cardiovascular and All Cause Mortality: The Boyd Orr Cohort. Heart 2005;91:894-8.

39 - Barlow SE, Dietz WH. Obesity Evaluation and Treatment: Expert Committee Recommendations. The Maternal and Child Health Bureau, Health Resources and Services Administration and the Department of Health and Human Services. Pediatrics 1998;102:E29.

40 - Committee on School health. Soft Drinks in Schools. Pediatrics 2004;113:152-4.

41 - Munoz KA, Krebs-Smith SM, Ballard-Barbash R, Cleveland LE. Food Intakes of Us Children and Adolescents Compared with Recommendations. Pediatrics 1997;100: 323-9.

42 - Giddings SS, Dennison BA, Birch LL, et al. Dietary Recommendations for Children and Adolescents: A Guide for Practitioners: Consensus Statement from the American Heart Association. Circulation 2005;112:2061-75.

43 - Vartanian LR, Schwartz MB, Brownell KD. Effects of Soft Drink Consumption on Nutrition and Health: A Systematic Review and Meta-Analysis. Am J Public Health 2007;97:667-75 .

44 - Krebs-Smith SM, Cook A, Subar AF, Cleveland L, Friday J, Kahle LL. Fruit and Vegetable Intakes of Children and Adolescents in the United States. Arch Pediatr Adolesc Med 1996;150:81-6.

45 - Neumark-Sztainer D, Story M, Hannan PJ, Croll J. Overweight Status and Eating Patterns among Adolescents: Where Do Youths Stand in Comparison with the Healthy People 2010 Objectives? Am J Public Health 2002;92:844$-1$.

46 - Larson NI, Neumark-Sztainer D, Hannan PJ, Story M. Trends in Adolescent Fruit and Vegetable Consumption, 1999-2004: Project Eat. Am J Prev Med 2007;32:147-50.

47 - Maynard M, Gunnell D, Emmett P, Frankel S, Davey Smith G. Fruit, Vegetables, and Antioxidants in Childhood and Risk of Adult Cancer: The Boyd Orr Cohort. J Epidemiol Community Health 2003;57:218-25.

48 - Bertheke Post G, De Vente W, Kemper HC, Twisk JW. Longitudinal Trends in and Tracking of Energy and Nutrient Intake over 20 Years in a Dutch Cohort of Men and Women between 13 and 33 Years of Age: The Amsterdam Growth and Health Longitudinal Study. Br J Nutr 2001;85:375-85.

49 - Lien N, Lytle LA, Klepp KI. Stability in Consumption of Fruit, Vegetables, and Sugary Foods in a Cohort from Age 14 to Age 21. Prev Med 2001;33:217-26.

50 - Dunn JE, Liu K, Greenland P, Hilner JE, Jacobs DR, JR.: Seven-Year Tracking of Dietary Factors in Young Adults: The Cardia Study. Am J Prev Med 2000;18:38-45.

51 - Gallagher AM, Robson PJ, Livingstone MB, et al. Tracking of Energy and Nutrient Intakes from Adolescence to Young Adulthood: The Experiences of the Young Hearts Project, Northern Ireland. Public Health Nutr 2006;9:1027-34. 
52 - Mikkila V, Rasanen L, Raitakari OT, Pietinen P, Viikari J. Consistent Dietary Patterns Identified from Childhood to Adulthood: The Cardiovascular Risk in Young Finns Study. Br J Nutr 2005;93:923-31.

53 - Addison CC, White MS, Jenkins BW, Young L. Combating the Epidemic of Obesity and Cardiovascular Disease: Perspectives from School-Aged Children. Int J Environ Res Public Health 2006;3:268-73.

54 - Barros H. Epidemiologia das Doenças Ateroscleróticas. Rev Port Cardiol 2000;19:7-74.

55 - Ferreira I, Twinsk JW, Van Mechelen W, Kemper HC, Stehouwer CD. Development of Fatness, Fitness, and Lifestyle from Adolescence to the Age of 36 Years: Determinants of the Metabolic Syndrome in Young Adults: The Amsterdam Growth and Health Longitudinal Study. Arch Intern Med 2005;165:42-8.

56 - Lagerros YT, Hsieh SF, Hsieh CC. Physical Activity in Adolescence and Young Adulthood and Breast Cancer Risk: A Quantitative Review. Eur J Cancer Prev 2004;13:512.

57 - Brosnahan J, Steffen LM, Lytle L, Patterson J, Boostrom A. The Relation between Physical Activity and Mental Health among Hispanic and Non-Hispanic White Adolescents. Arch Pediatr Adolesc Med 2004;158:818-23.

58 - Steptoe A, Butler N. Sports Participation and Emotional Wellbeing in Adolescents. Lancet 1996;347:1789-92.

59 - Nelson MC, Gordon-Larsen P. Physical Activity and Sedentary Behavior Patterns Are Associated with Selected Adolescent Health Risk Behaviors. Pediatrics 2006;117: 1281-90.

60 - Pate RR, Trost SG, Levin S, Dowda M. Sports Participation and Health-Related Behaviors among Us Youth. Arch Pediatr \& Adolesc Med 2000;154:904-11.

61 - Valois RF, Oeltmann JE, Waller J, Hussey JR. Relationship between Number of Sexual Intercourse Partners and Selected Health Risk Behaviors among Public High School Adolescents. J Adolesc Health 1999;25:328-35.

62 - Kulig K, Brener ND, McManus T. Sexual Activity and Substance Use among Adolescents by Category of Physical Activity Plus Team Sports Participation. Arch Pediatr Adolesc Med 2003;157:905-12.

63 - Aaron DJ, Dearwater SR, Aanderson R, Olsen T, Kriska AM, Laporte RE. Physical Activity and the Initiation of HighRisk Health Behaviors in Adolescents. Med Sci Sports Exerci 1995;27:1639-45.

64 - Tammelin T. A Review of Longitudinal Studies on Youth Predictors of Adulthood Physical Activity. Int J Adolesc Med Health 2005;17:3-12.

65 - Reilly JJ, Jackson DM, Montgomery C, et al. Total Energy Expenditure and Physical Activity in Young Scottish Children: Mixed Longitudinal Study. Lancet 2004;363:211-2.

66 - American Academy of Pediatrics: Children, Adolescents, and Television. Pediatrics 2001;107:423-6.

67 - Fonseca H, Gaspar de Matos M.Perception of Overweight and Obesity among Portuguese Adolescents: An Overview of Associated Factors. Eur J Public Health 2005;15:323-8.

68 - Li S, Chen W, Srinivasan SR, et al. Childhood Cardiovascular Risk Factors and Carotid Vascular Changes in Adulthood: The Bogalusa Heart Study. JAMA 2003;290:2271-6.

69 - Zieske AW, Malcom GT, Strong JP. Natural History and Risk Factors of Atherosclerosis in Children and Youth: The Pday Study. Pediatr Pathol Mol Med 2002;21:213-37.
70 - Berenson GS. Childhood Risk Factors Predict Adult Risk Associated with Subclinical Cardiovascular Disease. The Bogalusa Heart Study. Am J Cardiol 2002;90:3L-7L.

71 - Freedman DS, Dietz WH, Tang R, et al. The Relation of Obesity Throughout Life to Carotid Intima-Media Thickness in Adulthood: The Bogalusa Heart Study. Int J Obes Relat Metab Disord 2004;28:159-66.

72 - Lobstein T, Rigby N, Leach R. UE Platform on Diet, Physical Activity and Health. International Obesity Task Force Eu Platform Briefing Paper. [Cited 2005 Jul 12]. Available From: url http://europa.eu.int/comm/health/ ph determinants/life style/nutrition/documents/lotf en.pdf.

73 - Banegas JR, Lopes-Garcia E, Gutierrez-Fisac JL, GuallarCastillon P, Rodriguez-Artalejo F. A Simple Estimate of Mortality Attributable to Excess Weight in the European Union. Eur J Clin Nutr 2003;57:201-8.

74 - Marques-Vidal P, Dias CM. Trends in Overweight and Obesity in Portugal: The National Health Surveys 1995-6 and 1998-9. Obes Res 2005;13:1141-5.

75 - Nobre EL, Jorge Z, Macedo A, De Castro JJ. Trends of Weight, Height and Obesity in Young Portuguese Males: 1995-1999. Eur J Epidemiol 2003;18:1165-6.

76 - Santos AC, Barros H. Prevalence and Determinants of Obesity in an Urban Sample of Portuguese Adults. Public Health 2003;117:430-7.

77 - Padez C, Fernandes T, Mourão I, Moreira P, Rosado V. Prevalence of Overweight and Obesity in 7-9-Year-Old Portuguese Children: Trends in Body Mass Index from 1970-2002. Am J Hum Biol 2004;16:670-8.

78 - James PT, Leach R, Kalamara E, Shayeghi M. The Worldwide Obesity Epidemic. Obes Res 2001;9:228S-33.

79 - Wang Y, Monteiro C, Popkin BM. Trends of Obesity and Underweight in Older Children and Adolescents in the United States, Brazil, China, and Russia. Am J Clin Nutr 2002;75:971-7.

80 - Dietz WH. Health Consequences of Obesity in Youth: Childhood Predictors of Adult Disease. Pediatrics 1998;101:518-25.

81 - Srinivasan SR, Myers L, Berenson GS. Predictability of Childhood Adiposity and Insulin for Developing Insulin Resistance Syndrome (Syndrome X) in Young Adulthood: The Bogalusa Heart Study. Diabetes 2002;51:204-9.

82 - Engeland A, Bjorge T, Tverdal A, Sogaard AJ. Obesity in Adolescence and Adulthood and the Risk of Adult Mortality. Epidemiology 2004;15:79-85.

83 - Regidor E, Banegas JR, Gutierrez-Fisac JL, Dominguez V, Rodriguez-Artalejo F. Influence of Childhood Socioeconomic Circumstances, Height, and O-besity on Pulse Pressure and Systolic and Diastolic Blood Pressure in Older People. J Hum Hypertens 2006;20:73-82.

84 - Dietz WH. Periods of Risk in Childhood for the Development of Adult Obesity-What Do We Need to Learn? J Nutr 1997;127:1884S-6S.

85 - Freedman DS, Dietz WH, Srinivasan SR, Berenson GS. The Relation of Overweight to Cardiovascular Risk Factors among Children and Adolescents: The Bogalusa Heart Study. Pediatrics 1999;103:1175-82.

86 - Kohen-Avramoglu R, Theriault A, Adeli K. Emergence of the Metabolic Syndrome in Childhood: An Epidemiological Overview and Mechanistic Link to Dyslipidemia. Clin Biochem 2003;36:413-20.

87 - Dietz WH. Overweight in Childhood and Adolescence. N Engl J Med 2004;350:855-7. 
88 - Weiss R, Dziura J, Burgert TS, et al. Obesity and the Metabolic Syndrome in Children and Adolescents. N Engl J Med 2004;350:2362-74.

89 - Mustillo S, Worthman C, Erkanli A, Keeler G, Angold A, Costello EJ. Obesity and Psychiatric Disorder: Developmental Trajectories. Pediatrics 2003; 111:851-9.

90 - Levin S, Lowry R, Brown DR, Dietz WH. Physical Activity and Body Mass Index among Us Adolescents: Youth Risk Behavior Survey, 1999. Arch Pediatr Adolesc Med 2003; 157:816-20.

91 - Deforche B, Lefevre J, De Bourdeaudhuij I, Hills AP, Duquet W, Bouckaert J. Physical Fitness and Physical Activity in Obese and Nonobese Flemish Youth. Obes Res 2003;11:434-41.

92 - Whincup PH, Gilg JA, Donald AE, et al. Arterial Distensibility in Adolescents: The Influence of Adiposity, the Metabolic Syndrome, and Classic Risk Factors. Circulation 2005;112: 1789-97.

93 - Cole TJ, Bellizzi MC, Flegal KM, Dietz WH. Establishing a Standard Definition for Child Overweight and Obe-sity Worldwide: International Survey. BMJ 2000;320:1240-3.

94 - Kuczmarski RJ, Ogden CL, Guo SS, et al. 2000 Cdc Growth Charts for the United States: Methods and Development. Vital Health Stat 11 2002;1-190.

95 - Ramos E, Barros H. Family and School Determinants of Overweight in 13-Year-Old Portuguese Adolescents. Acta Paediatr 2007;96:281-6.

96 - Daniels SR, Arnett DK, Eckel RH, et al. Overweight in Children and Adolescents: Pathophysiology, Consequences, Prevention, and Treatment. Circulation 2005;111: 1999-2012.

97 - Koplan JP, Liverman CT, Kraak VI. Preventing Childhood Obesity: Health in the Balance: Executive Summary. J Am Diet Assoc 2005;105:131-8.

98 - Williams CL, Hayman LL, Daniels SR, et al. Cardiovascular Health in Childhood: A Statement for Health Professionals from the Committee on Atherosclerosis, Hypertension, and Obesity in the Young (Ahoy) of the Council on Cardiovascular Disease in the Young, American Heart Association. Circulation 2002;106:143-60.

99 - Wolf-Maierk, Cooper RS, Banegas JR, et al. Hypertension Prevalence and Blood Pressure Levels in 6 European Countries, Canada, and the United States. JAMA2003;289: 2363-9.

100 - Lawlor DA, Smith GD. Early Life Determinants of Adult Blood Pressure. Curr Opin Nephrol Hypertens 2005; 14:259-64.

101 - Yong LC, Kuller LH, Rutan G, Bunker C. Longitudinal Study of Blood Pressure: Changes and Determinants from Adolescence to Middle Age. The Dormont High School Follow-upStudy, 1957-1963 to 1989-1990. Am J Epidemiol 1993;138:973-83.

102 -Bao W, Threefoot SA, Srinivasan SR, Berenson GS. Essential Hypertension Predicted by Tracking of Elevated Blood Pressure from Childhood to Adulthood: The Bogalusa Heart Study. Am J Hypertens 1995;8:657-65.

103 - Miura K, Daviglus ML, Dyer AR, et al. Relationship of Blood Pressure to 25-Year Mortality Due to Coronary Heart Disease, Cardiovascular Diseases, and All Causes in Young Adult Men: The Chicago Heart Association Detection Project in Industry. Arch Intern Med 2001;161:1501$-8$.
104 - Macedo ME, Lima MJ, Silva AO, Alcantara P, Ramalhinho V, Carmona J. Prevalence, Awareness, Treatment and Control of Hypertension in Portugal: The Pap Study. J Hypertens 2005;23:1661-6.

105 - Santos AC, Lopes C, Barros H. Prevalence of Metabolic Syndrome in the City of Porto. Rev Port Cardiol 2004;23:45$-52$.

106 - Ramos E, Barros H. Prevalence of Hypertension in 13Year-Old Adolescents in Porto, Portugal. Rev Port Cardiol 2005;24:1075-87.

107 - Duarte JA, Guerra SC, Ribeiro JC, Mota RC. Blood Pressure in Pediatric Years (8-13 Years Old) in the Oporto Region. Rev Port Cardiol 2000;19:809-20.

108 - Macedo ME, Lopes L, Pereira A, De Freitas AF. Blood Pressure Normal Values in Children and Adolescents According to Age and Height. Rev Port Cardiol 1997;16: 679-82, 63.

109 - Sokol SI, Kapoor JR, Foody JM. Blood Pressure Reduction in the Primary and Secondary Prevention of Stroke. Curr Vasc Pharmacol 2006;4:155-60.

110 - Turnbull F, Neal B, Algert C, et al. Effects of Different Blood Pressure-Lowering Regimens on Major Cardiovascular Events in Individuals with and without Diabetes Mellitus: Results of Prospectively Designed Overviews of Randomized Trials. Arch Intern Med 2005;165:1410-9.

111 - Reaven GM. Banting Lecture 1988. Role of Insulin Resistance in Human Disease. Diabetes 1988;37:1595-607.

112 - Lakka HM LD, Laaka TA, Niskanen LK, et al. The Metabolic Syndrome and Total and Cardiovascular Disease Mortality in Middle-Aged Men. JAMA 2002;288:2709-16.

113 - Expert Panel on Detection, Evaluation, and Treatment of High Blood Cholesterol in Adults. Executive Summary of the Third Report of the National Cholesterol Education Program (Ncep) Expert Panel on Detection, Evaluation, and Treatment of High Blood Cholesterol in Adults (Adult Treatment Panel lii). JAMA 2001;285:2482-97.

114 - Andersen LB, Wedderkopp N, Hansen HS, Cooper AR, Froberg K. Biological Cardiovascular Risk Factors Cluster in Danish Children and Adolescents: The European Youth Heart Study. Prev Med 2003;37:363-7.

115 - Steinberg J, Daniels SR. Obesity, Insulin Resistance, Diabetes, and Cardiovascular Risk in Children: An American Heart Association Scientific Statement from the Atherosclerosis, Hypertension, and Obesity in the Young Committee (Council on Cardiovascular Disease in the Young) and the Diabetes Committee (Council on Nutrition, Physical Activity, and Metabolism). Circulation 2003;107:1448-53.

116 - Cruz ML, Weigensberg MJ, Huang TT, Ball G, Shaibi GQ, Goran MI. The Metabolic Syndrome in Overweight Hispanic Youth and the Role of Insulin Sensitivity. J Clin Endocrinol Metab 2004;89:108-13.

117 - Chen W, Srinivasan SR, Elkasabany A, Berenson GS. Cardiovascular Risk Factors Clustering Features of Insulin Resistance Syndrome (Syndrome $X$ ) in a Biracial (Black-White) Population of Children, Adolescents, and Young Adults: The Bogalusa Heart Study. Am J Epidemiol 1999;150:667-74.

118 - Clausen JO, Ibsen H, Ibsen KK, Borch-Johnsen K. Association of Body Mass Index, Blood Pressure and Serum Levels of Triglycerides and High-Density Lipoprotein Cholesterol in Childhood with the Insulin Sensitivity Index in Young Adulthood: A 13-Year Follow-Up. J Cardiovasc Risk 1996;3:427-33. 
119 - Vos LE, Oren A, Uiterwaal C, Gorissen WH, Grobbee DE, Bots ML. Adolescent Blood Pressure and Blood Pressure Tracking into Young Adulthood Are Related to Subclinical Atherosclerosis: The Atherosclerosis Risk in Young Adults (Arya) Study. Am J Hypertens 2003;16:549-55.

120 - Goodman E, Daniels SR, Morrison JA, Huang B, Dolan LM. Contrasting Prevalence of and Demographic Disparities in the World Health Organization and National Cholesterol Education Program Adult Treatment Panel lii Definitions of Metabolic Syndrome among Adolescents. J Pediatr 2004;145:445-51.

121 - Rodriguez-Moran M, Salazar-Vazquez B, Violante R, Guerrero-Romero F. Metabolic Syndrome among Children and Adolescents Aged 10-18 Years. Diabetes Care 2004;27:2516-7.

122 - Chen W, Bao W, Begum S, Elkasabany A, Srinivasan SR, Berenson GS. Age-Related Patterns of the Clustering of Cardiovascular Risk Variables of Syndrome $X$ from Childhood to Young Adulthood in a Population Made up of Black and White Subjects: The Bogalusa Heart Study. Diabetes 2000;49:1042-8.

123 - Duncan GE, Li SM, Zhou XH. Prevalence and Trends of a Metabolic Syndrome Phenotype among U.S. Adolescents, 1999-2000. Diabetes Care 2004;27:2438-43.

124 - De Ferranti SD, Gauvreau K, Ludwig DS, Neufeld EJ, Newburguer JW, Rifai N. Prevalence of the Metabolic Syndrome in American Adolescents: Findings from the Third National Health and Nutrition Examination Survey. Circulation 2004;110:2494-7.

125 - Ramos E. Health Determinants in Porto Adolescents. The Epiteen Cohort. Porto: University of Porto; 2006.
126 - Holland P, Berney L, Blane D, Smith GD, Gunnell DJ, Momtgomery SM. Life Course Accumulation of Disadvantage: Childhood Health and Hazard Exposure During Adulthood. Soc Sci Med 2000;50:1285-95.

127 - Smith GD, Hart C. Life-Course Socioeconomic and Behavioral Influences on Cardiovascular Disease Mortality: The Collaborative Study. Am J Public Health 2002;92:1295-8 .

128 - Smith GD, Hart C, Blane D, Hole D. Adverse Socioeconomic Conditions in Childhood and Cause Specific Adult Mortality: Prospective Observational Study. BMJ 1998;316:1631-5.

129 - Bush A. Asthma Research: The Real Action Is in Children. Paediatr Respir Rev 2005;6:101-10.

130 - Baik I, Devito WJ, Ballen K, et al. Association of Fetal Hormone Levels with Stem Cell Potential: Evidence for Early Life Roots of Human Cancer. Cancer Res 2005;65: 358-63.

131 - Forman MR, Cantwell MM, Ronckers C, Zhang Y. Through the Looking Glass at Early-Life Exposures and Breast Cancer Risk. Cancer Invest 2005;23:609-24.

\section{Correspondência:}

$\mathrm{Dr}^{\mathrm{a}}$ Elisabete Ramos

Serviço de Higiene e Epidemiologia

Faculdade de Medicina da Universidade do Porto Alameda Prof. Hernâni Monteiro 4200-319 Porto

e-mail: eliramos@med.up.pt 